\title{
Hypoxia-Induced Transcriptional Activation of Vascular Endothelial Growth Factor Is Inhibited by Serum
}

\author{
Gisela D'Angelo, ${ }^{1}$ Annie Ladoux, and Christian Frelin \\ Institut de Pharmacologie Mol éculaire et Cellulaire, CNRS UPR 411, 660 route des Lucioles, \\ Sophia-Antipolis, 06560 Val bonne, France
}

\begin{abstract}
Expression of vascular endothelial growth factor (VE GF) by cultured vascular smooth muscle cells was analyzed. Serum and hypoxia had nearly additive actions on VEGF mRNA expression. The function of the VEGF promoter in smooth muscle cells was analyzed using transient luciferase reporter assays. Serum and hypoxia stimulated expression of luciferase. The presence of hypoxia response element (HRE) was necessary for the hypoxic induction. AP-1 sequences located upstream of HRE and AP-2/Sp-1 sequences located downstream of HRE are not necessary. Hypoxic responses were best observed in serum-deprived cells. They were largely absent in serum-stimulated cells. Serum did not suppress the hypoxic response by interfering with the hypoxia sensor mechanism or with the signaling cascade that leads to the activation of HIF-1. It is concluded that growth-promoting cytokines regulate hypoxic gene induction in smooth muscle cells. ○ 2000 Academic Press
\end{abstract}

Hypoxic conditions encountered in various physiological and pathological processes stimulate angiogenesis, a process whereby new capillaries develop from preexisting blood vessels. Vascular endothelial growth factor (VEGF) (1), also known as vascular permeability factor (2), is believed to be one of the most important mediator of hypoxic angiogenesis (3). VEGF expression is activated by hypoxia in both transformed (4) and nontransformed cells (5). The action of hypoxia is mimicked by divalent metals ions such as cobalt, nickel and manganese and by iron chelators, such as desferrioxamine. Serum, growth factors and cytokines also upregulate expression of VEGF mRNAs (5-8). Hypoxia increases VEGF expression by stabilizing VEGF mRNAs and by activating gene transcription $(9,10)$. The mechanism by which hypoxia stimulates gene transcription has been partially elucidated. Hypoxia inducible factor

\footnotetext{
${ }^{1}$ To whom correspondence should be addressed. Fax: 334939577 08. E-mail: dangelo@ipmc.cnrs.fr.
}

1 (HIF-1) (11, 12), a basic helix-loop-helix heterodimer consisting of $\mathrm{HIF}-1 \alpha$ and ARNT, the aryl hydrocarbon nuclear translocator (13) is activated by hypoxia and binds to specific hypoxia-response elements (HRE) with a core sequence 5'-ACGTGG-3' (11, 14-17). Analysis of the VEGF promoter revealed the existence of additional binding sites for transcription factors such as AP-1, AP-2 and Spl (16, 18, 19). One AP-1 binding site located upstream of the HRE cooperates with HRE in the hypoxic induction of human VEGF promoter in C6 glioma cells (20). In other cell types, AP-2 and $\mathrm{Spl}$ transcription factors are required for transcriptional activation of VEGF gene by TGF - $\alpha$ (21), TNF- $\alpha$ (22) and p42/p44 MAP kinases under normoxic conditions (23).

Vascular smooth muscle cells encounter both hypoxia and growth promoting cytokines under conditions that are known to lead to the formation of atherosclerotic plaques (24). They produce VEGF and this production is thought to lead to the vascularization of the plaques and to contribute to their instability (25). The aim of this study was to analyse the regulation of VEGF expression in smooth muscle cells. The results show unexpected relationship between hypoxia and serum induction of VEGF gene transcription.

\section{MATERIALS AND METHODS}

Cell culture. Spontaneously immortalized rabbit aortic smooth muscle cells (Rbl cells) (26) were kindly provided by Dr. M. Nachtigal (University of South Carolina). They were cultured at $37^{\circ} \mathrm{C}$ and $5 \% \mathrm{CO}_{2}$ in Dulbecco's modified Eagle's medium (DMEM) supplemented with $10 \%$ fetal calf serum, $2 \mathrm{mM}$ L-glutamine, $100 \mathrm{U} / \mathrm{ml}$ penicillin and $100 \mu \mathrm{g} / \mathrm{ml}$ streptomycin. Serum-deprived cells were obtained by incubating cells for $24 \mathrm{~h}$ in DMEM supplemented with $0.5 \%$ serum. Hypoxic incubations were performed in an oxygenregulator incubator (Forma Scientific, Labtech, Model 3110) at $2 \%$ $\mathrm{O}_{2}$ for $6 \mathrm{~h}$ (RNA preparations) or $16 \mathrm{~h}$ (transfection assays).

Northern blot analysis. Total RNA was isolated according to the acid/phenol method of Chomczynski and Sacchi (27). Samples of RNA $(10 \mu \mathrm{g})$ were fractionated by denaturing electrophoresis through 1.3\% agarose gels, capillary blotted to charged nylon membrane (Zeta-Probe GT membrane, Bio-Rad) in 20× SSC buffer and covalently linked by ultraviolet irradiation. Membranes were prehy- 
bridized at $65^{\circ} \mathrm{C}$ for $3 \mathrm{~h}$ in $0.25 \mathrm{M}$ sodium phosphate $(\mathrm{pH} 7.2), 7 \%$ SDS. Hybridization was performed in the same buffer containing $10^{6}$ $\mathrm{cpm} / \mathrm{ml}$ of $\left(\alpha^{-}{ }^{32} \mathrm{P}\right)$-labeled cDNA probe (specific activity $>10^{9} \mathrm{cpm} / \mu \mathrm{g}$ DNA). Membranes were washed twice in $25 \mathrm{mM}$ sodium phosphate ( $\mathrm{pH} 7.2$ ) containing 5\% SDS and once in $25 \mathrm{mM}$ sodium phosphate (pH 7.2) containing $1 \%$ SDS for $30 \mathrm{~min}$ at $65^{\circ} \mathrm{C}$ each wash and hybridisation signals were quantitated using a phosphorimager. A 350 bp fragment from the rat VE GF cDNA (28) was used as a specific probe. $\left(\alpha{ }^{32} \mathrm{P}\right)$-labeled CDNA probe was prepared by using the Primea-Gene labeling system (Promega).

Reporter plasmid constructs. pVEGF-Luc, a vector consisting of a VEGF promoter fused to luciferase, was prepared as follow. A $1.15 \mathrm{~kb}$ DNA fragment corresponding to the functional promoter of the mouse VEGF gene (GenBank Accession No. U41383) was prepared by PCR from mouse genomic DNA by using the sense primer S1: 5'CAGGACTGGGCAGCTGGCCTAC-3' corresponding to positions 7697, and the reverse primer AS1: 5'-AAGCCTCTGCGCTTCTCACC-3' corresponding to positions 1211-1230. The pVEGF $\triangle A P-1-L u c$ construct was generated by PCR by using sense primer S2: 5'TGCCAGACTACACAGTGCATACGTG-3' corresponding to positions 282-307 and AS1. The pVEGF $\Delta$ AP-2/Spl and The pVEGF $\Delta$ AP-1 $\Delta$ AP2/Sp1 were prepared by PCR using primers S1 and S2 and the reverse primer AS2: 5'-CCACTACCGCGAAATGGAAAGCTAAA-3' corresponding to positions 1071-1096. PCR products were digested with restriction enzymes and ligated in front of luciferase CDNA in the Nhel and Xhol sites of pGL 3 basic vector (Promega).

pVEGF $\triangle$ HRE-Luc construct was obtained by deleting the pVEGFLuc construct from the core sequence of HRE (5'-ACGTGG-3') according to the spacing by overlap extension method (29). pVEGF $\triangle A P-1 /$ HRE-LUC was generated by PCR using a sense primer S3: 5'GTCTCACTCCCCGCCACTGACTAAC-3' corresponding to positions 321-345.

pH RE 4-Luc plasmid was kindly provided by Dr. Y. Fujii-Kuriyama (30). The pSV $\beta$ gal vector was from Promega.

Sequences of the products were confirmed by DNA sequence analysis using the dideoxy terminator sequencing method.

Transient transfection and luciferase assay. Rbl cells in 12 wellplates $\left(10^{5}\right.$ cells/well) were transfected with purified vectors (Wizard midi prep. Promega) by LipofectAmine (Gibco-BRL) according to the manufacturer's protocol. Briefly, a mixture of plasmids ( $2 \mu \mathrm{g}$ of the reporter plasmid and $0.2 \mu \mathrm{g}$ of $\mathrm{pSV} \beta \mathrm{Gal}$ vector) was diluted in $50 \mu \mathrm{l}$ OPTI-MEM (Gibco-BRL) and mixed with $8.4 \mu \mathrm{l}$ of LipofectAmine dissolved in the same volume. DNA/LipofectAmine complexes, diluted in $800 \mu$ l OPTI-MEM, were added to cells and incubated for $6 \mathrm{~h}$. All transfections were carried out in triplicate with aliquots of transfection mixture from a single pool. After $24 \mathrm{~h}$, cells were serum deprived for $24 \mathrm{~h}$ and incubated under either normoxic or hypoxic conditions. In some experiments, serum-deprived cells were stimulated with different concentrations of serum prior to exposure normoxia or hypoxia. Cells were then washed twice in phosphate buffered saline and lysed. Luciferase and $\beta$-galactosidase activities were measured in separated aliquots according manufacturer's instructions (Luciferase Assay System, Promega; Galacto-Light Plus, TROPIX, Inc.). Luciferase activities were divided by the $\beta$-galactosidase activities to correct for differences in transfection efficiency.

\section{RESULTS}

\section{Hypoxia and Serum Stimulate VEGF mRNA} Expression

Hypoxia and serum increase steady-state level of VEGF mRNAs in a variety of cells. Figure 1 compares the effects of hypoxia and serum on resting and growing smooth muscle cells. It shows that hypoxia stimu-

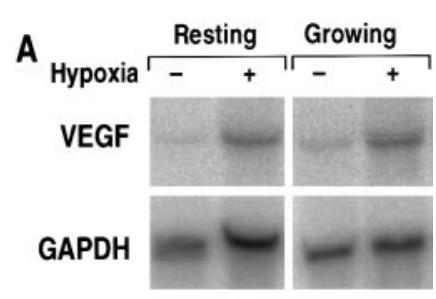

B

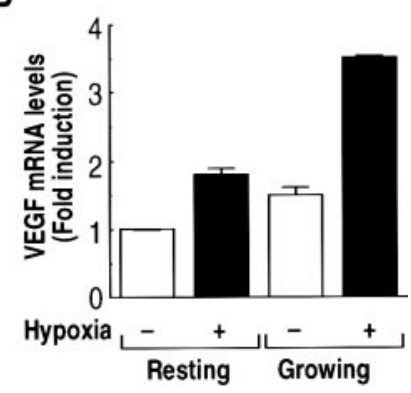

FIG. 1. Hypoxia and serum stimulate VEGF mRNA expression in smooth muscle cells. (A) Northern blot analysis of total RNA (10 $\mu \mathrm{g} / \mathrm{lane}$ ) extracted from resting and growing cells exposed to normoxia (-) or hypoxia (+) for $6 \mathrm{~h}$. The blot was hybridized to VEGF and GAPDH probe. (B) Normalized signal. Means \pm SEM $(n=3)$ are shown.

lated VEGF mRNA expression in the two types of culture conditions. Stimulation factors calculated after normalization of the VEGF signal to that of GAPDH were 1.8-fold and 3.5-fold in resting and exponentially growing cells respectively (Fig. 1B). Serum induced a 1.5-fold increase of VEGF mRNA levels in exponentially growing cells as compared to resting cells (Fig. $1 B$ ). Actions of serum and hypoxia were nearly additive.

\section{Functional Analysis of VEGF Promoter}

We next used transient transfection reporter assays to analyze the transcriptional regulation of VE GF gene expression in response to hypoxia and serum. The three regions of interest in the VEGF gene promoter are shown in the upper panel of Fig. 2. A series of constructs containing the functional VEGF promoter fused to luciferase cDNA and deleted of these sequences were generated. Constructs were transfected into smooth muscle cells and luciferase activity was assayed after exposing serum-deprived cells to normoxia or hypoxia. Figure 2 shows that the full-length VEGF promoter, conferred hypoxia inducibility to the reporter gene. The hypoxic response was suppressed after deletion of the internal core sequence of HRE. Hypoxic responses were retained with the pVEGF $\triangle$ AP1-Luc construct. Deletion of the AP-2/Sp1 sequences dramatically decreased expression of luciferase. A weak hypoxic response was retained, however.

We next analyzed the regulation by serum of the VEGF promoter function under normoxic and hypoxic 

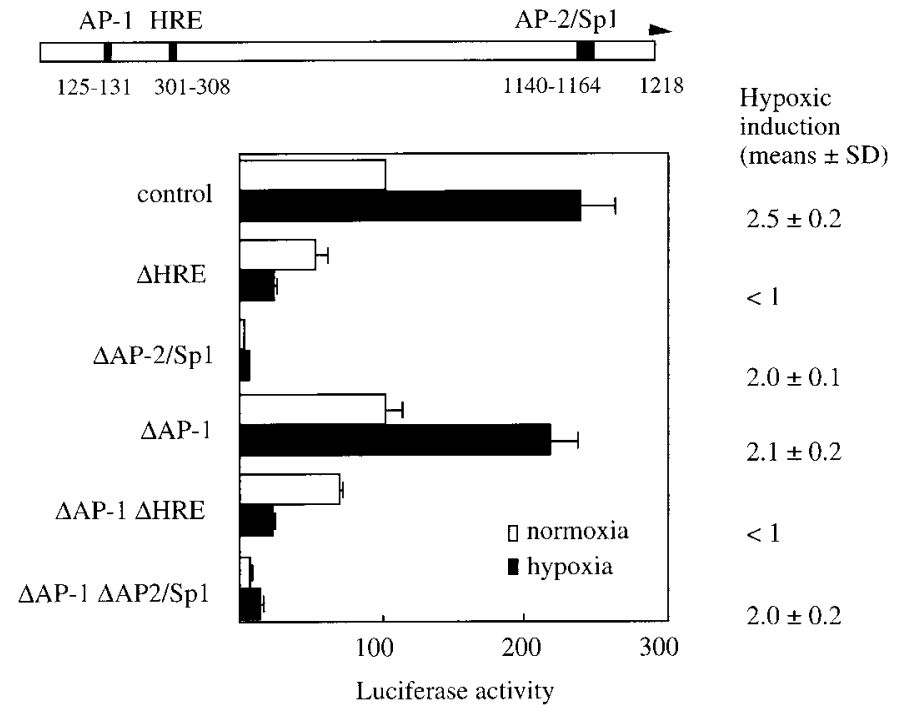

FIG. 2. Functional analysis of VEGF 5 '-flanking sequences in transient transfection assays. Upper panel: Positions of the regulatory sequences of interest in the mouse VEGF promoter. Lower panel: Normalized luciferase activities obtained with the different constructs. Means \pm SEM from four independent experiments, performed in triplicate, were calculated in arbitrary units and expressed as percentage change from the control.

conditions. pVEGF-Luc and pVEGF $\triangle$ AP-1-Luc constructs were transfected into smooth muscle cells. Cells were serum-deprived and then stimulated with different concentrations of serum under normoxic or hypoxic conditions. Figure 3 shows that serum stimulated the expression of luciferase, An identical result was observed with the pVEGF $\triangle A P-1-L u c$ construct, indicating that AP-1 sites did not contribute to the action of serum in smooth muscle cells. It also shows that large hypoxic responses were only observed with cells incubated in the presence of low concentrations of serum. Thus high serum concentration abolished hypoxic inducibility.

\section{Serum Does N ot Interfere with the Hypoxic Signaling} Cascade

Possible mechanisms for the above observations could be that serum blocked the hypoxic sensor mechanism, prevented the signaling cascade induced by hypoxia to activate HIF-1 or acted by the same mechanism as hypoxia (30). To test this hypothesis, we used a reporter plasmid that contained four tandemly repeated sequences of HRE upstream of SV40 promoter fused to luciferase cDNA (31). This construct did not contain the other regulatory sequences of the VEGF promoter. Serum-deprived transfected cells were stimulated with different concentrations of serum under normoxic or hypoxic conditions. Figure 4 shows that hypoxia induced transcriptional activation of the reporter plasmid independently of serum concentration

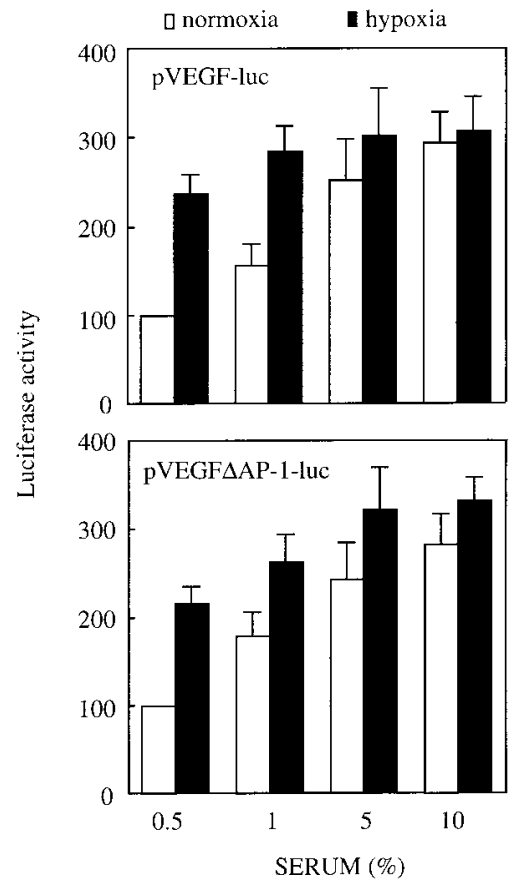

FIG. 3. Serum inhibited the hypoxic inducibility of the VEGF promoter. Cells were transfected with pVEGF-Luc (top) and pVEGF $\Delta$ AP-1-Luc (bottom) constructs. Luciferase activities were measured after $16 \mathrm{~h}$ of incubation under normoxic or hypoxic conditions and in the presence of the indicated concentrations of serum. Means \pm SEM from four independent experiments, performed in triplicate, were calculated in arbitrary units and expressed as percentage change from the control.

and that the hypoxic response defined as the ratio of luciferase activity obtained under hypoxic versus normoxic conditions was the same at all serum concentra-

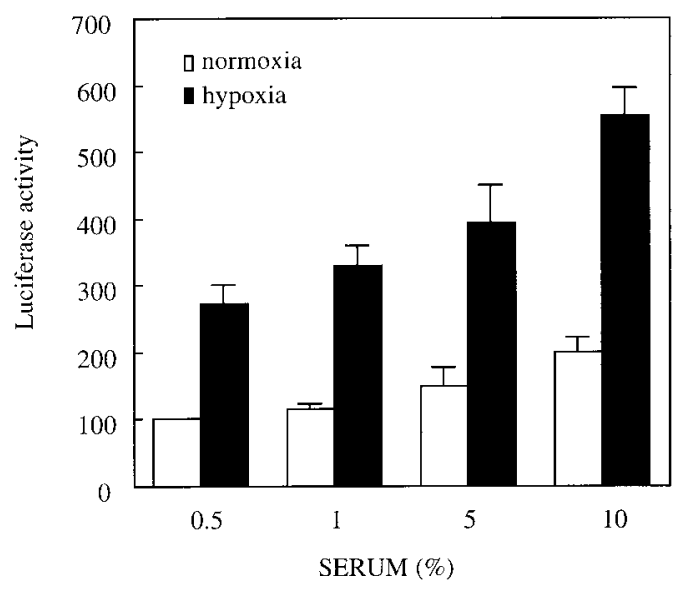

FIG. 4. Serum did not inhibit the hypoxic signaling cascade. Cells were transfected with a reporter plasmid containing four tandemly repeated HRE sequence coupled to pGL3 promoter reporter plasmid. Experiments were performed as described in the legend of Fig. 3. Means \pm SEM from four independent experiments, performed in triplicate, were calculated in arbitrary units and expressed as percentage change from the control. 
tions tested. These results thus indicate that serum did not inhibit the hypoxic inducibility by blocking HIF-1 signaling pathway.

\section{DISCUSSION}

This paper analyzes the transcriptional regulation of the mouse VEGF gene in response to hypoxia and serum in vascular smooth muscle cells. Our results first show that the AP-1 binding site that is located upstream of HRE does not contribute to the serum and hypoxic inducibilities in smooth muscle cells. This observation is in agreement with previous results using PC12 and Hep3B cells $(16,17)$. It differs from the results obtained in C6 cells (20). In these cells, AP-1 binding sites potentiate the action of hypoxia. These suggest that certain cis-acting elements may function in a cell-type-specific manner.

Our data also show that HRE is essential in mediating the hypoxic response of VEGF gene in smooth muscle cells. Similar results have been reported on the basis of a deletion analysis of rat and human VEGF 5'-flanking sequences in PC12 (16), C6 (20), Hep3B cells (17) and bovine pulmonary aortic endothelial cells (14). Our results show however that the deletion of only 6 bases from the core sequence of HRE is sufficient to suppress hypoxia-induced activation of the VEGF promoter.

Recent reports have demonstrated (i) that AP-2dependent DNA binding mediate the TGF $-\alpha$ induced transcriptional activation of VEGF (21), and (ii) that AP-2 and Sp1 binding sites were necessary for MAPK stimulation of VEGF promoter transcription (23). Our results show that this region of the VEGF promoter is also essential for VEGF gene transcription in smooth muscle cells. Deleting this region dramatically reduced expression of luciferase. It does not abolish the hypoxic response however.

The major observation of this paper is an unexpected crosstalk between serum and hypoxic regulation of the VEGF gene. Serum and hypoxia have nearly additive effects on the levels of VEGF mRNAs (Fig. 1). Serum inhibits the hypoxic inducibility in transient transfection reporter assays (Fig. 3). The inhibitory action of serum is not mediated by AP-1 binding site (Fig. 3). In addition, serum does not interfere with the hypoxic sensor or the signal transduction pathway leading to HIF-1 activation (Fig. 4). Although further analysis is required to identify the negative regulatory sequences that are activated by serum, this study points out the existence of complex actions of growth promoting cytokines on VEGF gene transcription in smooth muscle cells. They activate transcription by themselves, but they inhibit the hypoxic response. One obvious consequence is that hypoxic regulations of VEGF mRNA expression in resting and proliferating cells might be different. In resting cells, hypoxia may induce accumu- lation of VEGF mRNAs both by transcriptional and post transcriptional mechanisms. Hypoxia can only act via post transcriptional mechanisms in actively proliferating cells.

\section{ACKNOWLEDGMENTS}

We are grateful to Dr. M. Nachtigal for Rb-1 cells and to Dr. J . B. Michel for advice. This work was supported by the CNRS, ARC, Ligue Nationale contre le Cancer, and the Fondation de France. We are grateful to N. Seurin, N, Leroudier, F. Aguila, and J . Kervella for technical assistance.

\section{REFERENCES}

1. Leung, D., Cachianes, G., Kuang, W., Goeddel, D., and Ferrara, N. (1989) Science 246, 1306-1309.

2. Connoly, D. T., Olander, J . V., Heuvelman, D., Nelson, R., Monsell, R., Siegel, N., Haymore, B. L., Leimgruber, R., and Feder, J . (1989) J . Biol. Chem. 264,20017-20024.

3. Klagsbrun, M., and Soker, S. (1993) Curr. Biol. 3, 699-702.

4. Shweiki, D., Itin, A., Soffer, D., and Keshet, E. (1992) Nature 359, 843-845.

5. Ladoux, A., and Frelin, C. (1993) Biochem. Biophys. Res. Commun. 195, 1005-1010.

6. Goldberg, M. A., and Schneider, T. J . (1994) J . Biol. Chem. 269, 4355- 4359.

7. Gleadle, J . M., Ebert, B. L., Firth, J . D., and Ratcliff, P. J . (1995) Am. J . Physiol. 268, C1362-C1368.

8. Stavri, G. T., Hong, Y., Zachary, I. C., Breier, G., Baskerville, P. A., Yla-Herttuala, S., Risau, W, Martin, J . F., and Erusalimsky, J. D. (1995) FEBS Lett. 358, 311-315.

9. Levy, A. P., Levy, N. S., Wegner, S., and Goldberg, M. A. (1996) J . Biol. Chem. 271, 2746-2753.

10. Levy, N. S., Chung, S., Furneaux, H., and Levy, A. P. (1998) J . Biol. Chem. 273, 6417-6423.

11. Semenza, G. L., and Wang, G. L. (1992) Mol. Cell Biol. 12, 5447-5454.

12. Wang, G. L,.., and Semenza, G. L. (1993) J . Biol. Chem. 268, 21513-21518.

13. Wang, G. L., and Semenza, G. L. (1995) Proc. Natl. Acad. Sci. USA 92, 5510-5514.

14. Liu, Y., Cox, S. R., Morita, T., and Kourembanas, S. (1995) Circ. Res. 77, 638-643.

15. I keda, E., Achen, M. G., Breier, G., and Risau, W. (1995) J . Biol. Chem. 270,19761-19766.

16. Levy, A. P., Levy, N. S., Wegner, S., and Goldberg, M. A. (1995) J . Biol. Chem. 270, 13333-13340.

17. Forsythe, J . O., J iang, B. H., Iyer, N. V., Agani, F., Leung, S. W., Koos, R. D., and Semenza, G. L. (1996) Mol. Cell Biol. 9, 46044613.

18. Tischer, E., Mitchell, R., Hartman, T., Silva, M., Gospodarowicz, D., Fiddes, J. C., and Abraham, J. A. (1991) J . Biol. Chem. 266,11947-11954.

19. Shima, D. T., Kuroki, M., Deutsch, U., Ng, Y., Adamis, A. P., and D'Amore, P. A. (1996) J . Biol. Chem. 271, 3877-3883.

20. Damert, A., Ikeda, E., and Risau, W. (1997) Biochem. J . 327, 419- 423.

21. Gille, J ., Swerlick, R. A., and Caughman, S. W. (1997) EMBO J . 16, 750-759.

22. Yoshida, S. Ono, M., Shono, T., Izumi, H., I shibashi, T., Suzuki, H., and Kuwano, M. (1997) Mol. Cell Biol. 17, 4015- 4023. 
23. Milanini, J ., Vinals, F., Pouysségur, J ., and Pagès, G. (1998) J. Biol. Chem. 273, 18165-18172.

24. Inoue, M., Itoh, H., Ueda, M., Naruko, T., Kojima, A., Komatsu, R., Doi, K., Ogawa, Y., Tamura, N., Takaya, K., Igaki, T., Yamashita, J., Chun, T. H., Masatsugu, K., Becker, A. E., and Nakao, K. (1998) Circulation 98, 2108-2116.

25. Kuzuya, M., Satake, S., Esaki, T., Yamada, K., Hayashi, T., Naito, M., Asai, K., and Iguchi, A. (1995) J . Cell. Physiol. 164, 658- 667.

26. Nachtigal, M., Nagpal, M. L., Greespan, P., Nachtigal, S. A., and Legrand, A. (1989) In Vitro Cell Dev. Biol. 10, 892- 895.
27. Chomczynski, P., and Sacchi, N. (1997) Anal. Biochem. 162, 156-159.

28. Ladoux, A., and Frelin, C. (1994) Biochem. Biophys. Res. Commun. 194, 799-803.

29. Horton, R. N., Kay, Z. L., Ho, S. N., and Pease, L. R. (1990) Biotechniques 8, 5287-535.

30. Richard, D. E., Berra, E., Gothié, E., Roux, D., and Pouyssegur, J . (1999) J . Biol. Chem. 274, 32632-32637,

31. Ema, M., Taya, S., Yokotani, N., Sogawa, K., Matsuda, Y., and Fujii-Kuriyama, Y. (1997) Proc. Natl. Acad. Sci. USA 94, 42734278. 